\title{
Bomba patlamasına bağlı travma nedeni ile vasküler cerrahi geçiren yedi olgu
}

\section{Seven cases undergone vascular surgery caused by bomb explosion}

\author{
Ayşe Lafçı, Derya Gökçınar, Kevser Dilek Andıç, Nermin Göğüş
}

Ankara Numune Eğitim ve Araştırma Hastanesi, Anesteziyoloji ve Reanimasyon Kliniği, Ankara, Turkey

\begin{abstract}
Özet
Terörist saldırı sonucu travma geçiren olgularda erken tanı, hasar kontrol cerrahisi ve multidisipliner ekip çalışması önemlidir. Bomba patlaması sonucu yaralanma nedeni ile hastanemize getirilen yedi hasta, hastane kayıtlarından retrospektif olarak incelendi. Vasküler ameliyatlar gerektiren yedi hasta 22-56 yaşları arasında idi ve altı olgu erkek iken bir olgu kadın cinsiyette idi. Üç hastada abdominal yaralanma da vardı. Hastalara kardiyovasküler cerrahi kliniği hekimleri tarafından vasküler greft ile ya da primer damar onarımı yapıldı, abdominal yaralanması olan üç hastaya laparatomi ile barsak onarımı yapıldı. Travma hastalarında bilgisayarlı tomografik anjiografi yöntemi ile vasküler patolojinin ortaya konması, vakit kaybetmeden hasar kontrol cerrahisi uygulanması, yoğun bakım sürecinde yakın takip ve sonrasında rehabilitasyon, multidisipliner ekip çalışması gerektirir.
\end{abstract}

Anahtar Sözcükler: Bomba patlaması; hasar kontrol cerrahisi; vasküler yaralanma.

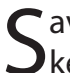
avaş hasar kontrol cerrahisi, savaş alanlarında yaralanan askerlere uygulanan bir acil müdahale prosedürüdür. Son yıllarda tüm dünyada sivil halkı hedef alan pek çok bombalı terör saldırısı meydana gelmektedir. Bu saldırılarda kullanılan el yapımı bombalar, yapımında kullanılan şarapnel parçalarından dolayı penetran özelliği ön planda olan silahlardır. ${ }^{[1]}$ Bu şarapnel parçaları insan vücudunda pek çok dokuda yaralanmaya neden olabilir. Özellikle vasküler dokularda meydana getirdiği hasarlarda meydana gelen abondan kanamalarda acil müdahale gereklidir. Acil müdahalede gecikme yüksek mortaliteye neden olabilir. Askeri hizmet veren hastaneler ve çalışanları bu tür yaralanmalarda tecrübe sahibidir. Günümüzde sivil hastaneler de böyle saldırılara maruz kalmış hastalarla karşılaşmak-

\begin{abstract}
Early diagnosis, damage control surgery and multidiciplinary team coordination is very essential in traumatic cases caused by terrorist attacks. Seven patient, admitted to our hospital, having injuries caused by bomb explosion were examined retrospectively from hospital records. The patients needed vascular operations were between 22-56 years old, six of them were male while one of them was female. There were abdominal injuries in three patients. Vascular greft or primary vein reparation were carried out on patients by cardiovascular surgery clinic operators. Intestine reparations by laparatomy were carried out in three patients having abdominal injuries. In traumatic patients, vascular patology, by computerized tomographic angioraphy and damage control surgery should be applied immediately. In addition, a close follow up in intensive care stage and afterwards rehabilitory, multidiciplinary team coordination is indispensible.
\end{abstract}

Keywords: Bomb explosion; damage control surgery; vascular injury.

tadır. Bombalı saldıılar sonucu acil servise çok sayıda yaralı, aynı anda getirildiği için yüklenme yaşanmaktadır. Hastaları karşılayan ekibin erken tanı ve müdahalesi hayat kurtarıcıdır. Hasar kontrol cerrahisinde mümkün olduğu kadar hızı bir şekilde kanamanın durdurulması ve gastrointestinal bütünlüğün sağlanması önemlidir. ${ }^{[2]}$

Ankara'nın Ulus semtindeki Ankara Garı kavşağında 10 Ekim 2015 tarihinde saat 10: 04'te düzenlenen intihar saldırısında 102 kişi hayatını kaybederken 391 kişi yaralı olarak kurtuldu. Saldırıyı takiben hastanemiz acil servisine 100 'den fazla yaralı getirildi. Biz bu olgu sunumu ile ağır yaralanmaya neden olan bombalı saldırıya maruz kalmış olgularda hasar kontrol cerrahisinin önemini vurgulamayı amaçladık.

Corresponding (illetişim): Ayşe Lafçı, Ankara Numune Eğitim ve Araştırma Hastanesi, Anesteziyoloji ve Reanimasyon Kliniği, Ankara, Turkey 


\section{Olgu Sunumu}

Gar patlaması olarak bilinen, bombalı terör eylemi sonucunda yaralı olarak hastanemiz acil servisine getirilen hastalar içerisinden büyük damar yaralanması geçiren ve kardiyovasküler cerrahi kliniği hekimleri tarafından damar onarımı ameliyatı uygulananlar retrospektif olarak incelendi. Hastaların karakteristikleri Tablo 1'de gösterilmiştir. Hastalar 22-56 yaşları arasında idi. Hastaların altısı erkek iken biri kadın cinsiyette idi. Hastalarda nemli soğuk ve soluk cilt, takipne, taşikardi, hipotansiyon, uykuya meyil ya da koma gibi hemorajik şok semptomları vardı. Hastaların tümünde alt ekstremitelerde büyük arter ve/veya venlerde yaralanma bulguları vardı. Olgu 1, 2, 3 ve 4'te kanayan alt ekstremitelerde olay yerinde bağlanmış turnikeler izlendi. Üç hastada ise alt ekstremitelerde büyük damar yaralanmasına ilaveten barsaklarda yaralanma vardı. Hızlı klinik değerlendirme ve bilgisayarlı tomografik anjiografi ile görüntülemeyi takiben hastalar acil operasyona alındı. ÇaIışma kapsamına alınan yedi hastaya acil serviste acil hekimleri ve anesteziyoloji ve reanimasyon hekimleri tarafından ilk müdahale yapıldıktan sonra genel cerrahi ve kardiyovasküler cerrahi hekimleri tarafından "Hasar kontrol cerrahisi" uygulandı. Dört hastaya (Olgu 1, 2, 3 ve 5) damar onarımı ameliyatı uygulanırken, üç hastaya (Olgu 4, 6 ve 7) eş zamanlı olarak hem damar onarımı hem de laparotomi ile barsak onarımı yapıldı. Hastalara yapılan ameliyatlar tablo 2 de gösterilmiştir. Hastaların tamamında ameliyatları sırasında dokular arasından metal bilyeler çıkarıldı (Şekil 1). Monitörizasyon EKG, intraarterial kanülasyon ile invaziv kan basıncı ölçümü ve nabız oksimetresi ile sağlandı. Periferik ve santral venöz kanülasyon yapıldı. Laboratuar incelemeleri kılavuzluğunda gerekli kan ürünü rep-

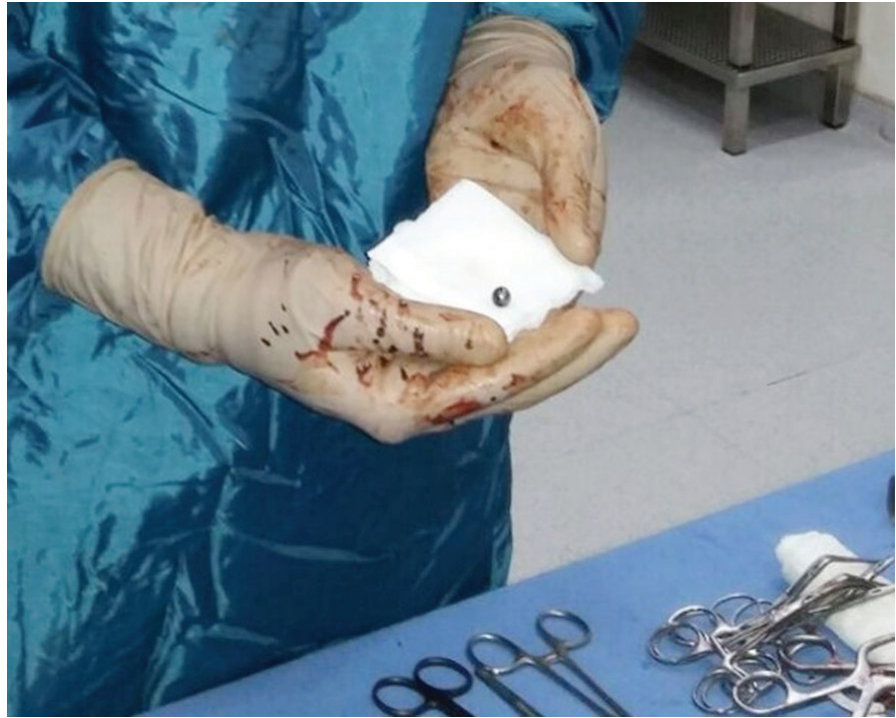

Şekil 1. Bomba tesirini arttırmak için kullanılan ve olgulardan çıkarılan metal bilyelerden bir tanesi.

lasmanları yapıldı (Tablo 2). Postoperatif dönemde hastalarımız hem Kalp -Damar Cerrahisi Yoğun Bakım Ünitesi'nde hem de Anestezi Genel Yoğun bakım Ünitesi'nde takip ve tedavi edilmeye devam edilmiştir. Hastalara parasetamol, metamizol, diklofenak ve remifentanil içeren analjezikler ile postoperatif ağrı tedavisi uygulandı. Olgu 7'de sağ diz altı amputasyonu gerekti. Bu nedenle Olgu 7'de postoperatif dönemde psikiyatri konsültasyonu gereksinimi oldu ve psikoterapi yapıldı. Olguların hastanede yatış süreleri 5-91 gün arasında idi ve hepsi iyileşerek taburcu edildi.

Tablo 1. Olguların özellikleri

\begin{tabular}{|c|c|c|c|c|c|c|}
\hline Olgu & Yaş & Cinsiyet & Klinik semptomlar & Görüntüleme yöntemi & Vasküler patoloji & ASA \\
\hline 1 & 56 & Erkek & $\begin{array}{l}\text { Hemorajik şok semptomları } \\
\text { Sol bacakta şarapnel giriş yeri } \\
\text { Sol popliteal bölgede şişlik }\end{array}$ & $\begin{array}{l}\text { Bilgisayarlı tomografik } \\
\text { anjiografi }\end{array}$ & $\begin{array}{l}\text { Sol popliteal arter } \\
\text { transeksiyonu }\end{array}$ & IV-E \\
\hline 2 & 22 & Erkek & $\begin{array}{c}\text { Hemorajik şok semptomları } \\
\text { Sol bacakta şarapnel giriş yerleri }\end{array}$ & $\begin{array}{l}\text { Bilgisayarlı tomografik } \\
\text { anjiografi }\end{array}$ & $\begin{array}{l}\text { Sol popliteal arter ve ven } \\
\text { transeksiyonu }\end{array}$ & IV-E \\
\hline 3 & 39 & Erkek & $\begin{array}{l}\text { Hemorajik şok semptomları } \\
\text { Sağ bacakta şarapnel giriş yerleri }\end{array}$ & $\begin{array}{l}\text { Bilgisayarlı tomografik } \\
\text { anjiografi }\end{array}$ & $\begin{array}{l}\text { Sağ popliteal arter } \\
\text { transeksiyonu }\end{array}$ & II-E \\
\hline 4 & 38 & Erkek & $\begin{array}{l}\text { Hemorajik şok semptomları } \\
\text { Abdominal ve sağ femoral } \\
\text { bölgede şarapnel giriş yerleri }\end{array}$ & $\begin{array}{l}\text { Bilgisayarlı tomografik } \\
\text { anjiografi }\end{array}$ & Sağ femoral ven kesisi & II-E \\
\hline 5 & 27 & Erkek & $\begin{array}{l}\text { Hemorajik şok semptomları } \\
\text { Sağ popliteal bölgede şarapnel } \\
\text { giriş yeri }\end{array}$ & $\begin{array}{l}\text { Bilgisayarlı tomografik } \\
\text { anjiografi }\end{array}$ & $\begin{array}{l}\text { Sağ popliteal arter } \\
\text { transeksiyonu }\end{array}$ & IV-E \\
\hline 6 & 32 & Erkek & $\begin{array}{l}\text { Hemorajik şok semptomları } \\
\text { Abdominal ve sol femoral } \\
\text { bölgede şarapnel giriş yerleri }\end{array}$ & $\begin{array}{l}\text { Bilgisayarlı tomografik } \\
\text { anjiografi }\end{array}$ & $\begin{array}{l}\text { Sol femoral arter } \\
\text { transeksiyonu }\end{array}$ & IV-E \\
\hline 7 & 25 & Kadın & $\begin{array}{l}\text { Hemorajik şok semptomları } \\
\text { Abdominal ve sağ uylukta } \\
\text { şarapnel giriş yerleri }\end{array}$ & $\begin{array}{l}\text { Bilgisayarlı tomografik } \\
\text { anjiografi }\end{array}$ & $\begin{array}{l}\text { Sağ iliak arter } \\
\text { tam kat yaralanması }\end{array}$ & IV-E \\
\hline
\end{tabular}


Tablo 2. Olgular için uygulanan hasar kontrol cerrahisi girişimleri, verilen kan ürünleri ve klinik sonuçlar

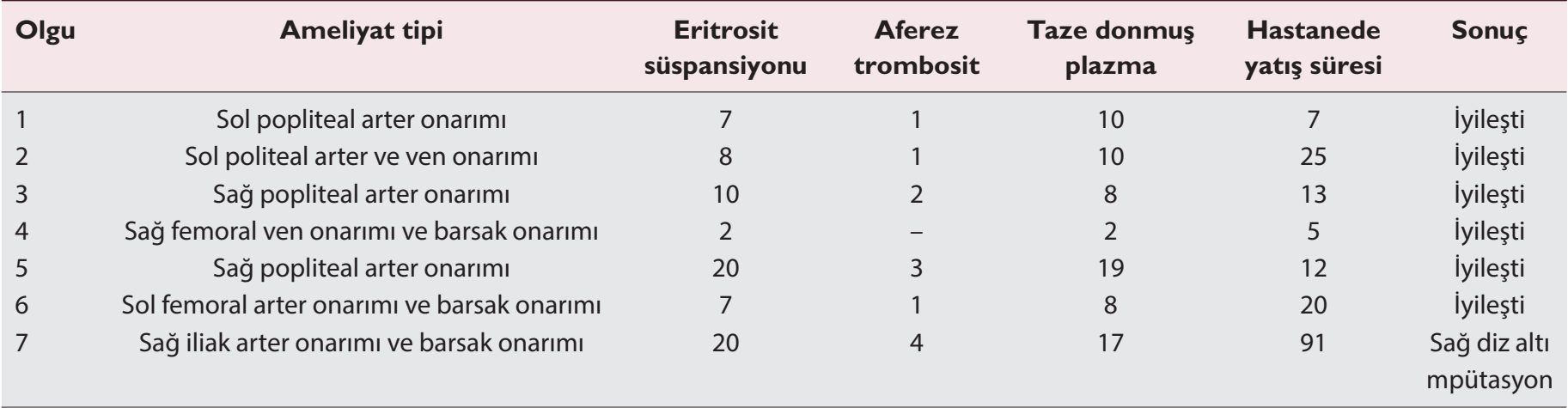

\section{Tartışma}

Bizim olgu sunumumuzda bahsi geçen bomba patlamasından kaynaklanan şarapnel parçaları hastalarda büyük damarlarda tam kat kesi ya da kısmi yaralanmalara neden olmuştur. Vasküler yaralanmalar akut kan kaybı ve buna bağlı organ yetmezliği oluşturabilen durumlardır. Erken tanı ve hızlı müdahale mortalite ve morbiditeyi azaltır. Ancak terörist saldırılarda aynı anda çok sayıda hasta kabul etmek zorunda kalan bir hastanede kaynaklar sınırlıdır. Kaynakların uygun kullanımı ile bu sorun aşılabilir. Stabil hastaların tanı ve tedavi prosedürleri bekletilirken stabil olmayan hastaların tanısal testleri ve acil cerrahi girişimleri bir an önce gerçekleştirilmelidir. ${ }^{[2]}$ Bu hastalarda "Hasar kontrol cerrahisi" kanamayı durdurmak ve barsak bütünlüğünü sağlamayı hedefler. "Ölümcül triad" olarak adlandırılan hipotermi, asidoz ve koagülopatiden kaçınabilmek için böyle travma hastalarına hızla hasar kontrol cerrahisi uygulamak gerekir. ${ }^{[3]}$ Bunların sağlanabilmesi hızlı triyaj, multidisipliner yaklaşım ve klinikler arası işbirliği gerektirmektedir. Eikermann ve arkadaşlarının, ${ }^{[4]}$ Boston Maratonu'nda meydana gelen bombalı saldırıda, hastaneye kabul edilen bir hasta ile ilgili raporunda, ilgili tüm branşların hastaya yaklaşımı ve müdahalesi rapor edilmiştir. Sağ bacak amputasyonu olan bu hastada olay yerinde ilk müdahalede turnike uygulaması ile kanamanın azaltıldığı ve hastanın hayatının güven altına alındığı özellikle vurgulanmıştır. Farklı bazı raporlarda kanamalı ekstremiteye sıkı şekilde uygulanan turnikenin hastalarda mortaliteyi önlediği gösterilmiştir. ${ }^{[5,6]}$ Bizim hastalarımızın bazılarına turnike uygulanmış olmakla birlikte yeterince efektif olmadığı gözlenmişti ama hastanemizin olay yerine çok yakın olması, hastalara erken müdahaleyi mümkün hale getirmişti.

Büyük damarların yaralanmasına bağlı hemorajik şokta olan hastalarda kan ürünleri replasmanı hayati önem taşır. Geçmişte travmatik hemorajik resüsitasyonda fazla oranda kristalloid kullanımı, bugün yerini çoğunlukla kan ürünlerine bırakmıştır. ${ }^{[7]}$ Fazla miktarda kristalloid kullanımının travma ilişkili koagülopatiyi arttırdığı bildirilmektedir. ${ }^{[8]}$ Travma hastalarında mümkün olabildiğince dengeli resusitasyonun önemi vurgulanmaktadır. ${ }^{[9]}$ Kan ürünleri replasmanında plazma, trombosit ve eritrosit süspansiyonunun 1:1:1 oranında verilmesi ve ameliyatta kanamayı azaltmak amaçlı permisif hipotansiyon öneril- mektedir. ${ }^{[9,10]}$ Hastanemizde bulunan kan merkezi, hastalar için gerekli kan ürünlerini hem kendi stoklarından, hem de Kızılay Kan Merkezi' inden hızlı bir şekilde temin etmiştir.

Travma hastalarında, ameliyat sonrası dönemde ağı kontrolü önemlidir. Yetersiz ağrı kontrolü postoperatif komplikasyonlarda artış ve uzamış hastane yatış süresine neden olabilir. İyi ağrı kontrolu hem psikolojik hem de maliyet etkin sonuçlar sağlar. Bu süreçte hastalarımıza ağrı kontrolü için çeşitli analjezikler uygulanmıştır.

\section{Sonuç}

Çok sayıda yaralanmalar ile ortaya çıkan bu patlamada cerrahlarla birlikte anesteziyoloji ve reanimasyon hekimlerinin de her safhada işbirliği içinde çalışmaları organizasyonun hızlanarak perioperatif bakımın etkin olmasını sağlamış ve hasta sonuçlarının başarılı olmasına katkıda bulunmuştur. Bu olgu sunumuyla bombadan kaynaklanan şarapnel ile büyük damar yaralanması olan hastalara acilen hasar kontrol cerrahisi uygulanmasının hayat kurtarıcı olduğu görülmüştür. Hastanemiz bu tip acil servis yüklenmelerinde deneyim sahibi olduğundan bu olgu sunumundaki hastalarımıza zamanında etkin müdahale yapılabilmiştir. Bu nedenle, multidisipliner işbirliği açısından ekiplerin koordine çalışmaya hazırlanmaları açııından belli zamanlarda simulasyon içeren eğitim çalışmalarının düzenlenmesinin faydalı olacağı kanısındayiz.

Çıkar çatışması: Bildirilmemiştir.

\section{Kaynaklar}

1. Heldenberg E, Givon A, Simon D, Bass A, Almogy G, Peleg K. Terror attacks increase the risk of vascular injuries. Front Public Health 2014;47:S1-5.

2. Traumabase Group. Paris terrorist attack: early lessons from the intensivists. Critical Care 2016;20:88.

3. Blackbourne LH. Combat damage control surgery. Crit Care Med 2008;36(7 Suppl):304-10.

4. Eikermann M, Velmahos G, Abbara S, Huang PL, Fagan SP, Hirschberg RE, et al. Case records of the Massachusetts General Hospital. Case 11-2014. A man with traumatic injuries af- 
ter a bomb explosion at the Boston Marathon. N Engl J Med 2014;370:1441-51.

5. King DR, van der Wilden G, Kragh JF Jr, Blackbourne LH. Forward assessment of 79 prehospital battlefield tourniquets used in the current war. J Spec Oper Med 2012;12:33-8.

6. Richey SL. Tourniquets for the controlof traumatic hemorrhage: a review of the literature. World J Emerg Surg 2007;2:28:S1-10.

7. Hess JR, Thomas MJ. Blood use in war and disaster: lessons from the past century. Transfusion 2003;43:1622-33.
8. Tieu BH, Holcomb JB, Schreiber MA. Coagulopathy: its pathophysiology and treatment in the injured patient. World J Surg 2007;31:1055-64.

9. Cantle PM, Cotton BA. Balanced Resuscitation in Trauma Management. Surg Clin North Am 2017;97: 999-1014.

10. Holcomb JB, Tilley BC, Baraniuk S, Fox EE, Wade CE, Podbielski $J M$, et al. Transfusion of plasma, platelets, and red blood cells in a 1:1:1 vs a 1:1:2 ratio and mortality in patients with severe trauma: the PROPPR randomized clinical trial. JAMA 2015;313:471-82. 